\title{
The effect of larval trematodes on the survival rates of two species of mud snails (Hydrobiidae) experimentally exposed to desiccation, freezing and anoxia
}

\author{
K.T. Jensen ${ }^{1}$, G. Latama ${ }^{2} \&$ K. N. Mouritsen ${ }^{1}$ \\ ${ }^{1}$ Department of Ecology and Genetics, Institute of Biological Sciences, University of \\ Aarhus; Ny Munkegade, Building 540, DK-8000 Aarhus C, Denmark \\ ${ }^{2}$ Marine Science Education Project, Universitas Hasanuddin; Ujung Pandang, Indonesia
}

\begin{abstract}
Digenetic trematodes are widespread among mud snails (Hydrobiidae) living in coastal lagoons and estuaries, but knowledge is generally lacking on their impact on these host organisms. We examined the survival rates of infected and non-infected experimental populations of two mud snail species, Hydrobia ventrosa (Montagu) and Hydrobia neglecta Muus, exposed to desiccation, freezing and anoxia in the laboratory. Our experiments indicated that non-infected groups of both species had similar survival rates after being subjected to desiccation and anoxia, whereas $H$. ventrosa survived freezing better than $H$. neglecta. However, infected groups of $H$. neglecta specimens subjected to desiccation showed significantly lower survival rates than non-infected groups. Infected and non-infected snails of both species exposed to freezing and anoxia exhibited similar survival rates. The possible mechanisms by which parasites influence their hosts are discussed. It is unlikely that the parasites in the present case mediate the coexistence of the two Hydrobia-species, because the snail with the highest reproductive effort $-H$. neglecta - showed lower infection rates in situ than its congener $H$. ventrosa.
\end{abstract}

\section{INTRODUCTION}

Most organisms are host to one or more parasite species. Several studies during the past few decades have demonstrated that parasites have considerable impact on the physiology, ecology and evolution of their host organisms (Lauckner, 1980; Holmes, 1983; Holmes \& Price, 1986; Price et al., 1986; Moore \& Gotelli, 1990; Thompson, 1990; Minchella \& Scott, 1991; Toft et al., 1991; Mouritsen \& Jensen, 1994). Although marine macrozoobenthic organisms often are intermediate hosts to several digenean trematode species (see Kinne, 1980), parasites have rarely been given proper attention in the physiological, behavioural and ecological studies of marine invertebrates (Lauckner, $1987 a_{\text {; }}$ Sousa, 1991). Given that more than half of a population may be infested (Lauckner, 1987b; Granovitch, 1992; Jensen \& Mouritsen, 1992), it is important to know how various abiotic factors and biotic processes influence infected and non-infected individuals in order to be able to understand population fluctuations. In general, hosts suffer from parasites, and for this reason stress factors could potentially be more damaging to parasitized than to non-parasitized individuals (Sousa \& Gleason, 1989).

Hydrobia-species have been used as model organisms for the study of different biotic processes, such as studies on niche structure, intra- and interspecific competition, and 
character displacement (Fenchel, 1975a, b; Hylleberg, 1975, 1986; Hylleberg \& Siegismund, 1987; Lassen \& Kristensen, 1978; Lassen \& Clark; 1979; Cherill \& James, 1987a, b). Recently, studies on their tolerance to toxic substances have been performed (Forbes, 1991). So far, none of these studies have considered that Hydrobia populations often exhibit high infection rates (Ankel, 1962; Lauckner, 1980, 1987b; Jensen \& Mouritsen, 1992). They are intermediate hosts for a diverse trematode fauna that utilize either water birds or fish as their final hosts (Ankel, 1962; Deblock, 1980; Lauckner, 1987b). Generally, parasites greatly influence their hosts' ecological relationship with competitors and predators (Holmes \& Price, 1986; Price et al., 1986; Minchella \& Scott, 1991).

Earlier studies have suggested that adverse abiotic conditions such as low winter temperatures (Hylleberg \& Siegismund, 1987), desiccation, or anoxic conditions (Lassen \& Kristensen, 1978) cause differential mortality rates in populations of Hydrobia ventrosa and Hydrobia neglecta. However, it is unknown to what extent parasites have influenced the snails' response to these environmental factors. Generally, parasitized snails are far more vulnerable to osmotic and thermal stress than non-parasitized snails (Lauckner, 1980,1987 a). To examine the influence of parasites on their hosts' tolerance to adverse environmental conditions, we conducted laboratory experiments with $H$. ventrosa and $H$. neglecta; both coexist in some Danish estuaries and shallow lagoons.

\section{MATERIALS AND METHODS}

Specimens of Hydrobia ventrosa and Hydrobia neglecta for the experiments were collected in a small, shallow-water lagoon $\left(5500 \mathrm{~m}^{2}\right)$ near Kalø, Denmark (see Lassen \& Kristensen, 1978) about two weeks before the experiments. The animals were kept at $14{ }^{\circ} \mathrm{C}$ in small tanks filled with seawater $(20 \%)$. The snails were fed with sediment sieved through a $63-\mu \mathrm{m}$ mesh. This sediment fraction is rich in microalgae, which are the most important food items for mud snails (Jensen \& Siegismund, 1980). All of the snails used in the experiments had shell lengths in the range of 3 to $4 \mathrm{~mm}$. The experiments were conducted during the spring of 1992.

To distinguish between infected and non-infected snails, each specimen was isolated in a small Petri-dish and exposed to light and high temperature $\left(25^{\circ} \mathrm{C}\right)$ for two days. This will generally cause a shedding of cercariae from infected specimens. Only snails infected with species belonging to Microphallidae were used in these experiments, because this group dominated the trematode fauna in Hydrobia in the lagoon. These microphallids utilize Hydrobia species as their first intermediate hosts, amphipods as their second intermediate host, and several species of water birds can be used as definitive hosts (Lauckner, 1987b).

The influence of desiccation, freezing and anoxia on the survival of parasitized and non-parasitized snails of the two species was examined in laboratory experiments. In each experiment, ten replicates from each combination of species $(H$. ventrosa/H. neglecta) that were either in parasitized or non-parasitized condition were subjected to the stress factor under consideration. Each experimental unit consisted of 10 snails. At the end of the experiments the snails were placed in seawater $(20 \%)$ at $14{ }^{\circ} \mathrm{C}$ for three hours, and the number of snails that survived were counted. If snails did not show active behaviour (locomotion), they were stimulated with a needle on the operculum, and those 
that responded by contraction were declared to be alive. Details of the three experiments are given below.

Desiccation experiment. This experiment was conducted at a constant temperature of $14{ }^{\circ} \mathrm{C}$. Each replicate consisted of a Petri-dish (3-cm diameter) containing ten snails. The duration of this experiment was 7 days.

Fre e $\mathrm{z}$ ing experime $\mathrm{nt}$. In this experiment, the experimental unit was defined as 10 -ml plastic tubes half-filled (to allow for expansion of the water during ice formation) with seawater $(20 \%)$. Each tube was sealed with a lid and established in a thermobath filled with an anti-freeze liquid ( $50 \%$ isopropanol). At the start of the experiment, small ice-crystals were added to each tube to stimulate the spontaneous formation of ice and to avoid hypersaline conditions at the bottom of the tubes. The temperature was kept at $-5{ }^{\circ} \mathrm{C}$. Pilot experiments had indicated that an experimental duration of four days was appropriate.

Anoxia experiment. The experimental unit was a small Petri-dish (3-cm diameter) filled with oxygen-free seawater (oxygen was replaced by nitrogen) and was covered with a piece of gauze bandage. The Petri-dishes were established for 19 days in a tube container filled with seawater $\left(20^{\circ} \mathrm{C}\right)$ in which anoxic conditions were maintained by supplying nitrogen continuously.

\section{Statistical analyses}

Differences in survival rates of $H_{y}$ drobia subjected to different environmental conditions were analysed for significance by analyses of variance using SPSS (Hull \& Nie, 1981). If data did not meet the assumption of homogeneity of variances (according to Cochran's test), they were arcsin-transformed. Data from the desiccation experiment exhibited some heterogeneity (Cochran's test, $p=0.021$ ). Accordingly, a lower probability level $(\mathrm{p}<0.01$ ) was used for significance tests (Underwood, 1981). Tukey's test was used to compare individual treatments (Day \& Quinn, 1989). Other details are indicated in the text.

\section{RESULTS}

Desic cation. Regarding the fraction of parasitized snails surviving desiccation, there were differences between the two Hydrobia species (Fig. 1A). In both parasitized and non-parasitized $H$. ventrosa, $30 \%$ of the individuals survived the seven days of desiccation. However, in $H$. neglecta the average survival rate declined from $42 \%$ in non-parasitized snails to $9 \%$ in parasitized snails. This interaction between the two factors (snail species and their parasitized or non-parasitized condition) was highly significant (Table 1). Tukey's test confirmed that the difference between parasitized and non-parasitized $H$. neglecta was significant $(\mathrm{p}<0.05)$ as was the difference in survival of $H$. ventrosa and parasitized $H$. neglecta.

Freezing. $H$. ventrosa survived freezing much better than $H$. neglecta (Fig. 1B). On average, $72 \%$ of the experimental population of $H$. ventrosa survived four days of freezing, whereas only $22 \%$ of the $H$. neglecta population survived. This difference between species was highly significant $(p<0.001$, Table 1$)$. The minor differences between parasitized and non-parasitized specimens in either species were not significant 


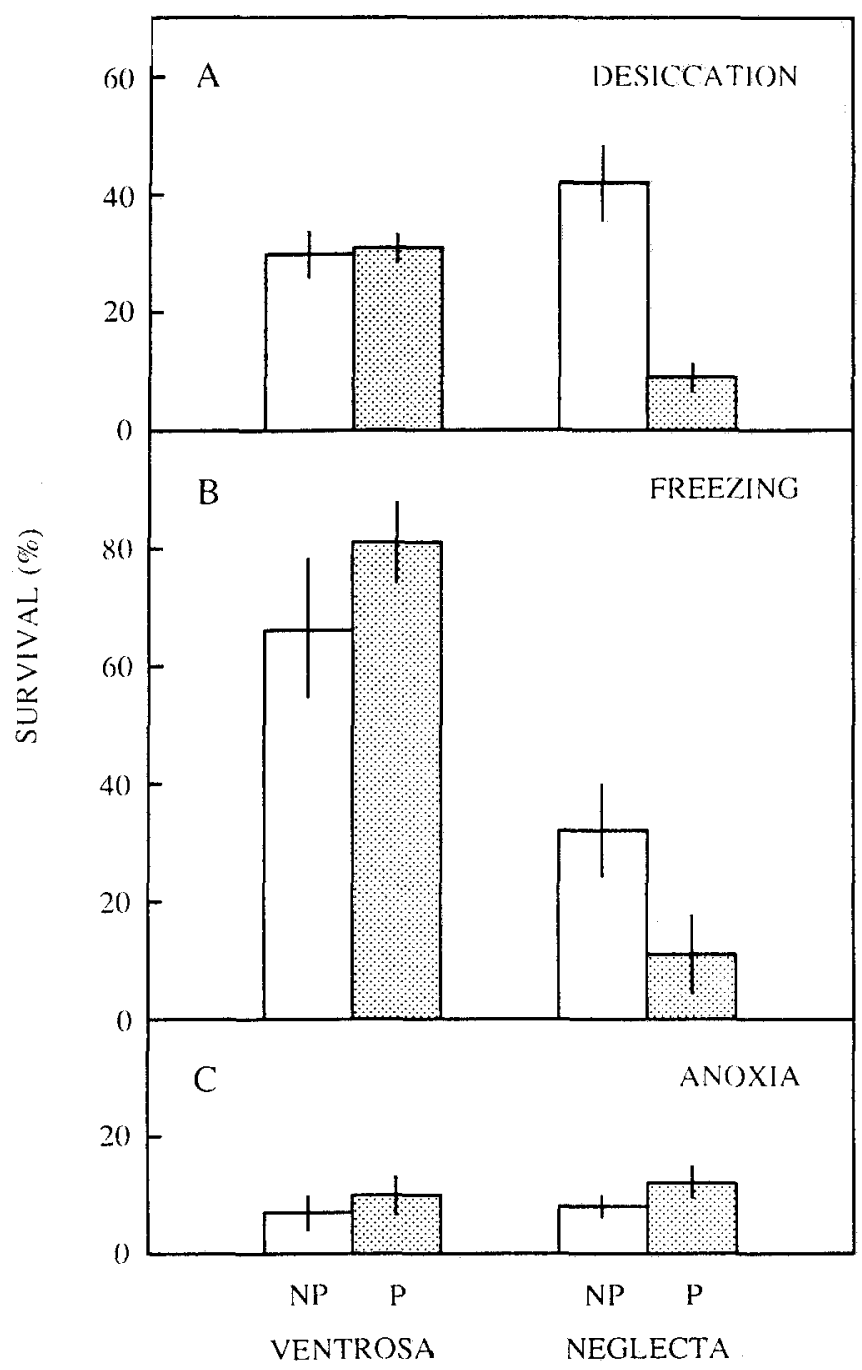

Fig. 1. Percentage survival (mean \pm S.E.) of $H$. ventrosa and $H$. neglecta exposed to (A) 7 days of desiccation; (B) 4 days of freezing; and (C) 19 days of anoxia (NP: non-parasitized, P: parasitized)

(Table 1). Thus, parasites had no significant impact on the survival of snails exposed to freezing.

A noxia. There was no difference in survival rates between parasitized and nonparasitized snails of either species subjected to 19 days of anoxia (Fig. 1C and Table 1). On average, $9 \%$ of all individuals survived this treatment. 
Table 1. Summary of analyses of variance for the three experiments: effects of species (H. neglecta) $H$. ventrosa) and snail condition (non-parasitized/parasitized) on the survival of snails under different experimental scenarios (desiccation, freezing and anoxia). Data on percentage survival have been arcsin-transformed

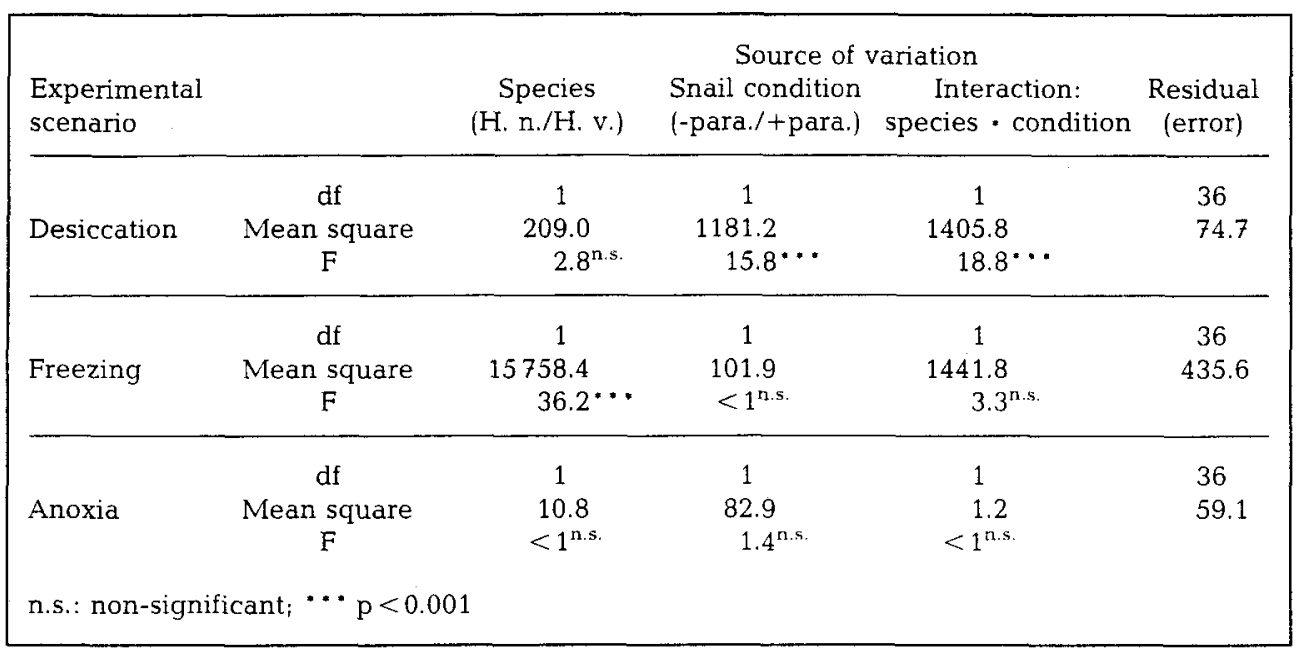

\section{DISCUSSION}

The two prosobranch snails, Hydrobia neglecta and Hydrobia ventrosa, are ecologically and morphologically very similar. They exhibit great distributional overlap within shallow water ecosystems (lagoons and estuaries) in northwestern Europe, but H. neglecta is much rarer than $H$. ventrosa (Muus, 1967; Fenchel, 1975a; Cherril \& James, 1985; Hylleberg, 1986; Barnes, 1993, 1994). Snails used for the present experiment were collected in a small lagoon in the Kattegat area, where the two species have coexisted for at least 13 years (Hylleberg, 1986). The question remains as to how congeneric species like the Hydrobia-species manage to exhibit a continuing coexistence within small semienclosed lagoons (low recolonization rates) like the one studied here. Experimental and observational data have indicated that the two snail species differ in their tolerance to desiccation, freezing and anoxia, and this is thought to mediate their coexistence (Muus, 1967; Lassen \& Kristensen, 1978; Hylleberg, 1986; Hylleberg \& Siegismund, 1987).H. neglecta seems better adapted to dessication and anoxia than $H$. ventrosa, whereas $H$. ventrosa survives freezing better. For unparasitized snails the present results did not support any significant difference between the two species regarding their tolerance to desiccation and anoxia, but corroborated that $H$. ventrosa survives freezing better than $H$. neglecta. It has to be recognized that the survival rates obtained in the present experiments depend on both the duration of the experiments and the parameter settings (i.e. temperature, humidity, etc.). In this regard, the experiments may not necessarily simulate natural conditions. Nevertheless, the differences observed among the species are more interesting than the absolute survival rates. Of the two species, H. neglecta showed a significantly higher mortality rate when infected with microphallids and subjected to desiccation, whereas parasites did not interfere with stress tolerance in $H$. 
ventrosa. Similar experiments on the influence of trematodes on the survival rates of intermediate snail hosts subjected to extreme but realistic environmental variables are scarce. Sousa \& Gleason (1989) carried out a study of this kind on Cerithidea californica. No significant difference was found in the survival rates experienced by infected and uninfected snails exposed to extremes in water temperature, salinity or desiccation. Low levels of oxygen was the only condition that caused higher mortality in infected snails than in healthy ones (Sousa \& Gleason, 1989). Exposure to extremely high temperatures $\left(35^{\circ} \mathrm{C}\right)$ and low $\left(-2{ }^{\circ} \mathrm{C}\right)$ temperatures are known to cause increased mortality of parasitized Nassarius reticulatus (in temperate regions) (Tallmark \& Norrgren, 1976). It has also been reported that parasites may weaken the snail host's resistance to various toxicants or other pollutional stress factors (Guth et al., 1977), but the effect of parasites upon resistance depends on the stages of the parasites. However, as shown in the present study, congeneric snails may differ in their response to the same trematode species. Furthermore, it has been observed that different species of trematodes may influence their hosts differently (Lauckner, 1980). At present we do not know by which mechanisms the parasites interfere with the host's tolerance to stress factors: neither do we know enough about the differences in the physiology of the two Hydrobia-species to explain their different tolerances to the various environmental factors. Many investigations have demonstrated that host starvation in invertebrates results in similar effects to those of infection (James, 1965). For this reason, parasitized snails may be less tolerant to stress factors. As an example, to perform anaerobic metabolism, organisms use stored energy reserves (glycogen). Some morphological features such as the permeability of the shell and operculum as well as behavioural features may influence the snail's tolerance to desiccation. It has been observed that there is a general correspondence between the zonational sequence of the animals on intertidal shores and the amount of water loss the species can tolerate (Newell, 1970). It could be envisaged that parasites interfere with such tolerances, for instance, by disturbing the calcification processes in molluscs (Davies \& Erasmus, 1984). Both freezing and desiccation could result in an increase in the concentration of solutes in the body fluid (because of evaporation or freezing of water). The ability to tolerate exceptional increases in osmotic concentrations might then allow snails to survive freezing and desiccation. Indeed, Hydrobia-species are known for their euryhalinity. To what extent the mechanisms regulating the snails' tolerance to high osmotic concentrations are damaged by parasites is unknown.

Considering the often dense infrapopulations of microphallid larvae in Hydrobia it is remarkable that the parasites do not have a stronger effect on the snails' tolerance to stress factors than observed in the present study. However, this seems to be in accordance with the prudent-parasite model for parasite-host co-evolution (sensu Esch \& Fernandez, 1993). For the present parasites, whose transmission success is dependent on viable intermediate hosts, it is essential that the snails as hosts survive the environmental conditions that they naturally may experience. As expressed by Dawkins (1982), a parasitized host represents an extended phenotype of the parasite. Thus, we may expect that selection will favour parasites that have little pathogenic effect on their hosts. However, it may not necessarily be that simple (Freeland, 1986; Dobson \& Merenlender, 1991; Esch \& Fernandez, 1993). The selective advantages to a parasite with low levels of host pathogeneity depend on the parasite's reproductive and transmission modes as well as its competitive interactions with other members of the same parasite infracommunity. 
Individual parasite species may have co-evolved with a particular snail as intermediate host but not with the snail's congeneric relatives. If the prudent-parasite model is acceptable, this could explain differential effects of the same parasite species on different host species. In the present case, $H$. neglecta could be a reservoir host, and this might explain the lower prevalences of microphallids seen in $H$. neglecta than in $H$. ventrosa (see below).

Data on the reproductive effort of Hydrobia from Danish lagoons (including the one studied here) indicate that $H$. neglecta allocates more energy to reproductive purposes than $H$. ventrosa (Lassen, 1979; Lassen \& Clark, 1979). However, comprehensive studies in the U.K. have failed to confirm this difference between $H$. neglecta and $H$. ventrosa (Barnes, 1993, 1994). Presuming that this discrepancy reflects regional differences in lifehistory traits and not artifacts, $H$. neglecta has a higher reproductive rate than $H$. ventrosa in our area. The two species have similar food niches (Fenchel \& Kofoed, 1976). Both species exhibit similarly increased mortality rates as a function of both inter- and intraspecific densities. Given the higher reproductive rate of $H$. neglecta over $H$. ventrosa, we would predict that the former will, in the course of time, out-compete the latter in the Kalø lagoon. However, fluctuating environmental conditions cause variability in the two species' mortality rates. The question is whether parasites are an additional factor promoting coexistence of the two snail species. Parasite-mediated coexistence has been demonstrated from other ecosystems (Holmes \& Prices, 1986; Price et al., 1986; Minchella $\&$ Scott, 1991; Schall, 1992). In these cases the dominant competitors are selectively infected by parasites that have a detrimental impact on the well-being of the host species. In $1991, H$. neglecta was the dominant snail, as it exhibited roughly $80 \%$ of the Hydrobia population in the studied lagoon, but the frequency of parasites was less in $\mathrm{H}$. neglecta $(8 \%)$ than in $H$. ventrosa $(25 \%)$ (Latama, 1992). Thus, no proof was found that parasites contribute to the coexistence of the two snails. However, the prevalence of parasites shows temporal variation. From the same locality, Lauckner (1987b) found that $27 \%$ of the Hydrobiids were infected by only one microphallid species (Maritrema subdolum). Nonetheless, based on the 1991 data, parasites seem to be more detrimental to $H$. ventrosa than to $H$. neglecta, because the castrating effect of parasites probably has a greater impact on the density of the snail population than any reduction these parasites cause in snail longevity (Sousa \& Gleason, 1989).

In conclusion, the available data do not support the hypothesis of parasite-mediated coexistence in the present case. Desiccation will cause mortality in most snails, but less in non-infected $H$. neglecta than in other groups. However, as the numbers of parasitized $H$. neglecta are relatively small, the relative amounts of the two groups will not change much. Nonetheless, parasites will play an important role in the population dynamics of the two snail species. Prevalences of parasites at $27 \%$ (Lauckner, 1987b) will surely influence the population development in the present biotope, particularly so in species without a direct development. Recolonisation from the outside proceeds slowly because of limited water exchange between the lagoonal water and the estuarine water outside.

Acknowledgements. We thank J. Hylleberg for valuable discussions during this study, and we appreciate the assistance of A. H. Jensen and H. I. Jensen in the laboratory. Financial support was given by DANIDA and the "Indonesian Marine Science Programme" (to G. L.) and the Carlsberg Foundation (to K. N. M.). 


\section{LITERATURE CITED}

Ankel, F., 1962. Hydrobia ulvae Pennant und Hydrobia ventrosa Montagu als Wirt larvaler Trematoden. - Vidensk. Meddr dansk. naturh. Foren. 124, 1-100.

Barnes, R. S. K., 1993. Life-history strategies in contrasting populations of the coastal gastropod Hydrobia. III. Lagoonal versus intertidal marine $H$. neglecta. - Vie Milieu 43, 73-83.

Barnes, R. S. K., 1994. Investment in eggs in lagoonal Hydrobia ventrosa and life-history strategies in north-west European Hydrobia species. - J. mar. biol. Ass. U.K. 74, 637-650.

Cherrill, A. J. \& James, R., 1985. The distribution and habitat preferences of four species of Hydrobiidae in East Anglia. - J. Conch. 32, 123-133.

Cherrill, A. J. \& James, R., 1987a. Character displacement in Hydrobia. - Oecologia 71, 618-623.

Cherrill, A. J. \& James, R., 1987b. Evidence for competition between mudsnails (Hydrobiidae): a field experiment. - Hydrobiologia 150, 25-31.

Davies, T. W. \& Erasmus, D. A. 1984. An ultrastructural study of the effect of parasitism by larval Schistosoma mansoni on the calcium reserves of the host, Biomphalaria glabrata. - Cell Tissue Res. 236, 643-649.

Dawkins, R., 1982. The extended phenotype. The gene as the unit of selection. Freeman, Oxford, 307 pp.

Day, R. W. \& Quinn, G. P., 1989. Comparisons of treatments after an analysis of variance in ecology.Ecol. Monogr. 59, 433-463.

Deblock, S., 1980. Inventaire des trématodes larvaires parasites des mollusques Hydrobia (Prosobranches) des côtes de France. - Parassitologia 22, 1-105.

Dobson, P. \& Merenlender, A., 1991. Coevolution of macroparasites and their hosts. In: Parasite-host associations - Coexistence or conflict? Ed. by C. A. Toft, A. Aeschlimann \& L. Bolis. Oxford Science Publ., Oxford, 83-101.

Esch, G. W. \& Fernández, J. C., 1993. A functional biology of parasitism. Chapman \& Hall, London, $337 \mathrm{pp}$.

Fenchel, T., 1975a. Factors determining the distribution patterns of mud snails (Hydrobiidae). Oecologia 20, 1-17.

Fenchel, T., 1975b. Character displacement and coexistence in mud snails (Hydrobiidae). - Oecologia $20,19-32$.

Fenchel, I. \& Kofoed, L., 1976. Evidence for exploitative interspecific competition in mud snails (Hydrobiidae). - Oikos 27, 367-376.

Forbes, V. E., 1991. Response of Hydrobia ventrosa (Montagu) to environmental stress: effects of salinity fluctuations and cadmium exposure on growth. - Funct. Ecol. 5, 642-648.

Freeland, B., 1986. Arms races and covenants: the evolution of parasite communities. In: Community ecology. Ed. by J. Kikkawa \& D. J. Anderson. Blackwell, London, 289-308.

Granovitch, A. I., 1992. The effect of trematode infection on the population structure of Littorina saxatilis (Olivi) in the White Sea. In: Proceedings of the Third International Symposium on Littorinid Biology. Ed by J. Grahame, P. J. Mill \& D. G. Reid. The Malacological Society of London, London, 255-263.

Guth, D. J., Blankespoor, H. D. \& Cairns, J., 1977. Potentiation of zinc stress caused by parasitic infection of snails. - Hydrobiologia 55, 225-229.

Holmes, J. C., 1983. Evolutionary relationships between parasitic helminths and their hosts. In: Coevolution. Ed by D. J. Futuyma \& M. Slatkin. Sinauer, Sunderland, Mass., 161-185.

Holmes, J. C. \& Price, P. W., 1986. Communities of parasites. In: Community ecology. Ed. by J. Kikkawa \& D. J. Anderson. Blackwell, London, 187-213.

Hull, C. H. \& Nie, N. H., 1981. SPSS update 7-9. New procedures and facilities for releases 7-9. McGraw-Hill, New York, $402 \mathrm{pp}$.

Hylleberg, J., 1975. The effect of salinity and temperature on egestion in mud snails (Gastropoda: Hydrobiidae): I. A study on niche overlap, - Oecologia 21, 279-289.

Hylleberg, J., 1986. Distribution of hydrobiid snails in relation to salinity, with emphasis on shell size and co-existence of the species. - Ophelia (Suppl.) 4, 85-100.

Hylleberg, J. \& Siegismund, H. R., 1987. Niche overlap in mud snails (Hydrobiidae): freezing tolerance. - Mar. Biol. 94, 403-407. 
James, B. L., 1965. The effects of parasitism by larval Digenea on the digestive gland of the intertidal prosobranch, Littorina saxatilis (Olivi) subsp. tenebrosa (Montagu). - Parasitology 55, 93-115.

Jensen, K. T. \& Siegismund, H. R., 1980. The importance of diatoms and bacteria in the diet of Hydrobia-species. - Ophelia (Suppl.) 1, 193-199.

Jensen, K. T. \& Mouritsen, K. N., 1992. Mass mortality in two common soft-bottom invertebrates, Hydrobia ulvae and Corophium volutator - the possible role of trematodes. - Helgoländer Meeresunters. 46, 329-339.

Kinne, O., 1980. Diseases of marine animals: General aspects. In: Diseases of marine animals. Ed. by O. Kinne. Wiley, New York, 1, 13-73.

Lassen, H. H., 1979. Reproductive effort in Danish mudsnails (Hydrobiidae). - Oecologia 40, 365-369.

Lassen, H. H. \& Kristensen, J. H., 1978. Tolerance to abiotic factors in mudsnails (Hydrobiidae). Natura jutl. 20, 243-250.

Lassen, H. H. \& Clark, M., 1979. Comparative fecundity in three Danish mudsnails (Hydrobiidae). Ophelia $18,171-178$.

Latama, G., 1992. Occurrence and impact of larval trematodes on the ecology of Hydrobia neglecta Muus and $H$. ventrosa (Montagu) (Gastropoda: Hydrobiidae) in estuarine environments. Thesis, Univ. of Aarhus, Aarhus, $34 \mathrm{pp}$.

Lauckner, G., 1980. Diseases of Mollusca: Gastropoda. In: Diseases of marine animals. Ed. by O. Kinne. Wiley, New York, 1, 311-424.

Lauckner, G., $1987 \mathrm{a}$. Ecological effects of larval trematode infestation on littoral marine invertebrate populations. - Int. J. Parasitol. 17, 391-398.

Lauckner, G., 1987b. Effects of parasites on juvenile Wadden Sea invertebrates. In: Proceedings of the 5th International Wadden Sea Symposium. Ed. by S. Tougaard \& S. Asbirk. The National Forest and Nature Agency \& The Museum of Fisheries and Shipping, Esbjerg, 103-121.

Minchella, D. J. \& Scott, M. E., 1991. Parasitism: a cryptic determinant of animal community structure. - Trends Ecol. Evolut. 6, 250-254.

Moore, J. \& Gotelli, N. J., 1990. Phylogenetic perspective on the evolution of altered host behaviours: a critical look at the manipulation hypothesis. In: Parasitism and host behaviour. Ed. by C. J. Barnard \& J. M. Behnke. Taylor \& Francis, London, 193-229.

Mouritsen, K. N. \& Jensen, K. T., 1994. The enigma of gigantism: effect of larval trematodes on growth, fecundity, egestion and locomotion in Hydrobia ulvae (Pennant) (Gastropoda: Prosobranchia). - J. exp. mar. Biol. Ecol. 181, 53-66.

Muus, B., 1967. The fauna of Danish estuaries and lagoons. Distributions and ecology of dominating species in the shallow reaches of the mesohaline zone. - Meddr Danm. Fisk.- og Havunders. 5, $1-316$

Newell, R. C., 1970. Biology of intertidal animals. Elek, London, 555 pp.

Price, P. W., Westoby, M., Rice, B., Atsatt, P. R., Fritz, R. S., Thompson, J. N. \& Mobley, K., 1986. Parasite mediation in ecological interactions. - A. Rev. Ecol. Syst. 17, 487-505.

Schall, J. J., 1992. Parasite-mediated competition in Anolis lizards. - Oecologia 92, 58-64.

Sousa, W. P., 1991. Can models of soft-sediment community structure be complete without parasites? - Am. Zool. 31, 821-830.

Sousa, W. P. \& Gleason, M., 1989. Does parasitic infection compromise host survival under extreme environmental conditions? The case for Cerithidea californica (Gastropoda: Prosobranchia). Oecologia $80,456-464$.

Tallmark, B. \& Norrgren, G., 1976. The influence of parasitic trematodes on the ecology of Nassarius reticulatus (L.) in Gullmar Fjord (Sweden). - Zoon 4, 149-154.

Thompson, S. N., 1990. Physiological alterations during parasitism and their effects on host behaviour. In: Parasitism and host behaviour. Ed. by C. J. Barnard \& J. M. Behnke. Taylor \& Francis, London, 64-94.

Toft, C. A., Aeschlimann, A. \& Bolis, L., 1991. Introduction: coexistence or conflict. In: Parasite-host associations - Coexistence or conflict? Ed. by C. A. Toft, A. Aeschlimann \& L. Bolis. Oxford Science Publ., Oxford, 1-12.

Underwood, A. J., 1981. Techniques of analysis of variance in experimental marine biology and ecology. - Oceanogr. mar. Biol. 19, 513-605. 